\title{
Evaluation of Business Practice in Contract Research Organizations (CROs) of Selected CROs in Hyderabad
}

\author{
Venkateswara Rao Papineni \\ Research Scholor, Department of Management \\ Rayalaseema University, Kurnool 518007, Andhra Pradesh, India \\ vraopapineni@gmail.com
}

\begin{abstract}
This research covered 350 CRO company employees in 32 CRO organizations largely at Hyderabad to collect data with a structured questionnaire. Questions were designed based on objectives and hypothesis which were basically to understand the drivers of growth and sustenance factors in CRO industry, using which a strategy would be made by each CRO company. Factor analysis helped to arrive at such factors. A comparative study was conducted between large, medium and small CROs which found that the re is no common strategy or parameters for CRO across the globe because of disagreements we discovered between each type of CROs while responding to the questions during our personal interviews. Such agreements and disagreements were captured by chi-square analysis which helped to fabricate parameters and strategy for each CRO instead of working on a common strategy for every type of CRO.

In the final recommendation, the strategies for HR, Financial, Quality and overall business were made in this research and thesis writing. While predominantly the HR strategy seems to drive all other strategies of financial, quality etc., as per the present stud, the industry seems to have given a low priority for marketing in business development.
\end{abstract}

Keywords: CRO (Contract Research Organization), CRO HR Practices, CRO Quality Assurance, CRO Financial Practices, CRO Business Development practices.

\section{INTRODUCTION}

A Contract Research Organization (CRO) is a service organization which provides support to the pharmaceutical industry and offers various\| pharmaceutical research that is essential for conducting Analytical testing (for both Pharma and Non-Pharma companies), Preclinical testing, Clinical Research and Clinical Trials and Biopharma, in the present boom when various complications are involved in the drug discovery process.

Globally, outsourcing of research and development (R\&D) in pharmaceutical industry has become a norm. Some of the factors that drive outsourcing are: increasing competition, complexity of product development, need for financial flexibility, desire to bring products to the market quickly, difficulties in finding qualified personnel, high costs of recruiting, and increasing number of start-up firms.

Clinical development has become increasingly complex and is one of the key areas for outsourcing. Contract Research Organizations (CROs) are often able to provide clinical trial services with a higher level of expertise or specialization faster and at a lower cost than the sponsor company could.

\section{NEED FOR THE STUDY}

2.1. The CRO industry in India and globally is the back bone of health care industry in general which provides testing services, Research and Development and drug discovery assistance to the Pharma and allied industries. This industry is facing several challenges of financial, regulatory and market fragmentation because of which not many CROs are able to survive and meet the world class standards required for the vital industry. The profitability is far less than the cost of capital and the capital itself is scarce because not many funding agencies come forward to invest in CRO industry in view of better and profitable domains like software attract capital. The entrepreneurs therefore are forced to find capital from internal sources which are limited whereas CRO industry requires huge capital because of cost of instrumentation and research and worldwide marketing required for survival. 
2.2. The industry is controlled by several regulatory authorities such as USFDA, MHRA, EMA, NABL, WHO etc., which continuously impose restrictions in the name of standardization without looking at the obsolescence and capital requirements. The technology changes very fast and there by necessitating scarping of expensive instruments in short time even before their ROI is achieved. The pay back periods are very longer but equipment replacement comes much faster due to need for continuous upgradation as per customer demands.

2.3. This industry has to be handled by highly skilled people both at top and middle and lower levels in the CRO organization, laboratories and support services. Such people migrate very fast leaving very high rates of attrition in the organization due to better opportunities, skill development and fluctuating manpower demand locally and globally. A person who is trained with time and resources for a year or two will change job for better opportunities and CRO Company ever remains as a training ground.

2.4. In view of the above and many other challenges described in this thesis, the industry requires elaborate research to find solutions for the aforesaid challenges. But unfortunately, the Universities and research organizations never focused academic studies on the problems confronted by this industry. Government has also not recognized CRO industry as 'core sector' and the problems remain and growing leaps and bounds, thereby forcing the industry to remain unprofitable. Therefore, this research is undertaken at $\mathrm{PhD}$ level to study exhaustively the issues relating to the origin, growth and development of CRO industry in India, which is expected to provide policy guidelines to the Govt. as well as industry circles.

Hence this research is undertaken.

\section{OBJeCtives OF THE STUDY}

3.1. To study the significant business parameters adapted by CRO companies at Hyderabad.

3.2. To evaluate whether there is any significant correlation between business practices of large, medium and small CRO organizations.

3.3. To study particularly the human resource practices and find any differences between the target groups.

3.4. To study particularly QA practices and find any differences between the target groups.

3.5. To study particularly Financial practices and find any differences between the target groups.

3.6. To recommend an over-all business strategy for each type of strategy.

\section{RESEARCH HYPOTHISIS}

The study has a broad hypotheses which proposes the evaluation of business practices among various Contract Research Organizations. The Research Hypothesis covers the essential practices for running in the CROs. (The Human Resources practices, Quality Assurances practices, Business de velopment practices and the financial best practices). The research hypothesis is further clarified to bring out the impact of HR, QA, BD and Financial practices on the overall profitability of the organizations.

\section{REVIEW LITERATURE}

This review of literature is prepared based on researcher's study of several books, journals, inkdustry reports and previous research works of faculty and scholars in various universities particularly in India. It was noted that not many research studies were available on the subject CRO industry business practices because this industry is very specialized and does not seem to have adequate attention of Govt., or other national bodies or regulatory agencies. However, several documents were referred and consultations were made with industry experts who were instrumental in putting together pieces of information available at various sources, which were not in the limelight. It has taken a period of three years to consolidate the small fragments of data from hidden sources by visiting libraries, reading books, journals and industry reports. The following books were immense use in preparing this literature.

The research works and published articles have thrown light on the following review of literature:

\subsection{James Buchan (2004)}

The paper considers how policy has been defined and evaluated in other sectors. Essentially there are two sub-themes: how have policy interventions been defined? and how have the effects of these 
interventions been measured in order to identify which interventions are most effective? In other words, what is "good" policy?

The paper argues that it is not only the organizational context that differentiates the health sector from many other sectors, in terms of policy. Many of the measures of organizational performance are also unique. "Performance" in the health sector can be fully assessed only by means of indicators that are sector-specific. These can focus on measures of clinical activity or workload, on measures of output or, less frequently, on measures of outcome

The paper also stresses the need for a "fit" between the best business policy approach and the organizational characteristics, context and priorities, and for recognition that so-called "bundles" of linked and coordinated policy interventions will be more likely to achieve sustained improvements in organizational performance than single or uncoordinated interventions.

\subsection{Sreedhar (2010)}

It is mandatory to conduct the pre clinical and clinical trials for approval of drugs by any regulatory authority. Most importantly the clinical trial data will be accepted by the regulatory authority if it is been conducted in a registered clinical trial centre. Clinical trials were primarily conducted in the United States. There was paradigm shift from the west to east for conducting the clinical trials because of the cost factor. Developing countries such as India, China and South East Asian countries have tapped the very potential clinical trial market. India has exploited the potential for clinical research by attracting various international and domestic pharmaceutical companies.

Jyoti Jaiswal, K. K. Tripathi (2008) : According to this new research study on the sector called "Booming Clinical Trials Market in India", the clinical trial outsourced market in India is forecasted to grow at a compound annual growth rate( CAGR) of around 31\% during 2010-12. Presently, the market is characterized by the dominance of phase III and phase II trials, which currently hold more than $80 \%$ of the market. India has the largest pool of patients in many diseases, including cancer and diabetes. The study also points out that India's biggest advantage is its low cost. It contains all the requis ite information that will help clients to draw up market strategies and assess opportunity areas in India's clinical trial market. Clinical trials in India are $44 \%$ less expensive than US trials.

Arun Bhatt in 2009 in his article 'Pharmacovigilance for clinical trials in India: Current practice and areas for reform' wrote that keeping in mind India's increasing participation in multinational trials, this article explores potential areas of Indian pharmacovigilance, requiring reform and provides recommendations for building a robust safety reporting system. Finally, the need to formulate an allencompassing pharmacovigilance guideline for India, in sync with global practice cannot be overemphasized.

\subsection{Cygnus Business Consulting \& Research}

Which has published an article 'INDIA - Emerging contract Research Hub' mentioned that Contract Research is one of the major steps in the development of new drugs to address diseases. All drugs should be undergoing different phases of clinical trials to safeguard mankind. The pharmaceutical industry invests between 10 to $20 \%$ of annual sales revenues in research and development, which is far higher than other research-based sectors.

Prathap Tharyan (2006) : This paper traces the development of the contract research Registry-India (CTRI) against the backdrop of the inequities in healthcare and the limitations in the design, conduct, regulation, oversight and reporting of clinical trials in India. It describes the scope and goals of the CTRI, the data elements it seeks and the process of registering clinical trials. It reports progress in trial registration in India and discusses the challenges in ensuring that healthcare decisions are informed by all the evidence.

\subsection{Ne e raj Gilhotra (2007)}

A pharmaceutical company conducts extensive pre-clinical or laboratory research i.e. testing of chemical compounds in animal and human cells. The compounds are also extensively tested in animals. If this stage of testing gives positive results, a pharmaceutical company provides this data to the regulatory body requesting its approval to begin testing the drug in humans. This testing of drug in humans is called Clinical Trial. 


\section{RESEARCH DESIGN}

The study covers data collection by secondary and primary methods. The secondary data sources included books, periodicals, previous research studies, industry report, government archives and allied published materials. The primary data was collected using a structured questionnaires on a sample of 350 respondents in 32 CRO companies and Hyderabad and other major cities. The sampling method used was stratified convenient sampling is shown in the Table 1:

Table1. Population and Sample size for the current study

\begin{tabular}{|l|l|l|}
\hline Category & Population & Sample Size \\
\hline Large & 340 & 83 \\
\hline Medium & 740 & 181 \\
\hline Small & 350 & 86 \\
\hline
\end{tabular}

\section{ANALYSIS TOOLS AND TECHNIQUES}

The data was analyzed in several stages starting from coding and tabulation. Data being in frequencies, the chi-square analys is with $(\mathrm{p}<=0.05)$ level of significance was conducted to compare the opinions and factors between various Contract Research Organizations followed by factor analys is on each question using SPSS and SAS software packages.

\section{Primary Data Analysis \& Discussion}

8.1. When the target groups were enquired about the method of training carried in their CRO which is ever changing, the large and medium CROs opted for On the Job Training while the small CROs go for any type of training that fit into their situation. Figure 1 explains the same.

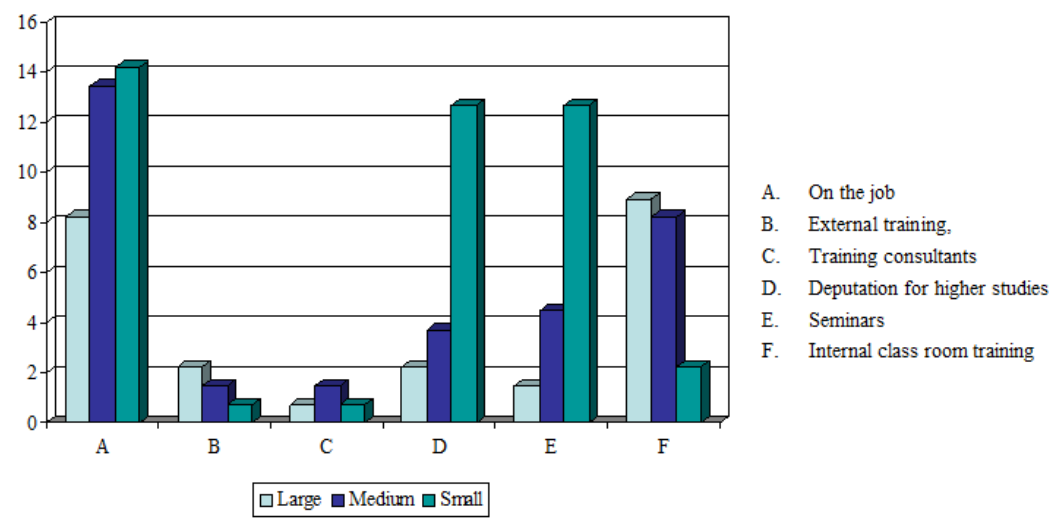

Figure1. Methods employed for training in various CROs

8.2. When asked the target groups if their organization apply effective time management techniques (customer schedules) to their business operations, ie., regarding the turnaround time and maintenance of master schedule, the chi-square analysis conducted on feed back forms obtained through the questionnaires proved that time management techniques (customer schedules) are uniformly followed as the critical parameter of business by all CROs. The research observations proved that many CROs are finding it difficult to manage TAT. However, this is make or break parameter for business development and therefore should be given overriding priority over the business goals. Figure 2 explains the same.

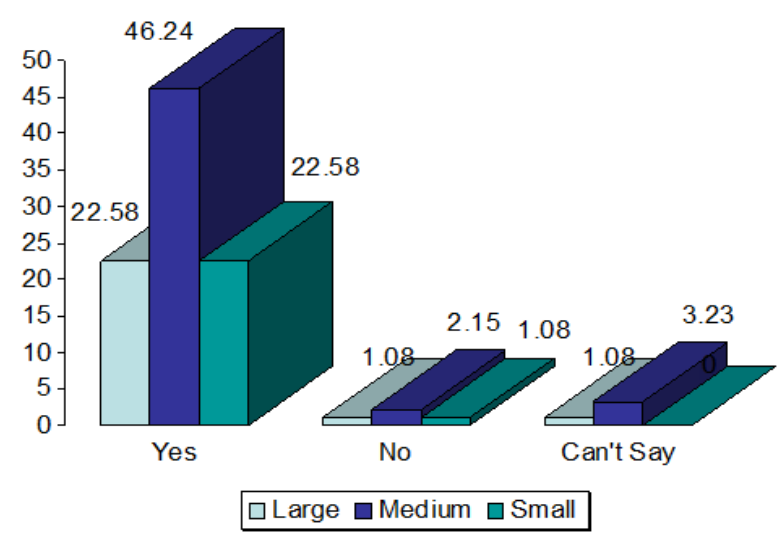

Figure2. Response if Effective Time Management Techniques (customer schedules) are applied by various CROs 
8.3. When enquired the target groups if their organizations were having sufficient working capital to operate their business, uniform feedback from large and small CROs saying they have sufficient working capital where as the medium size CROs reported mixed reaction of yes and no for working capital and therefore it is recommended that medium CROs must focus on securing adequate working capital for the yearly running of company. Figure 3 explains the same.

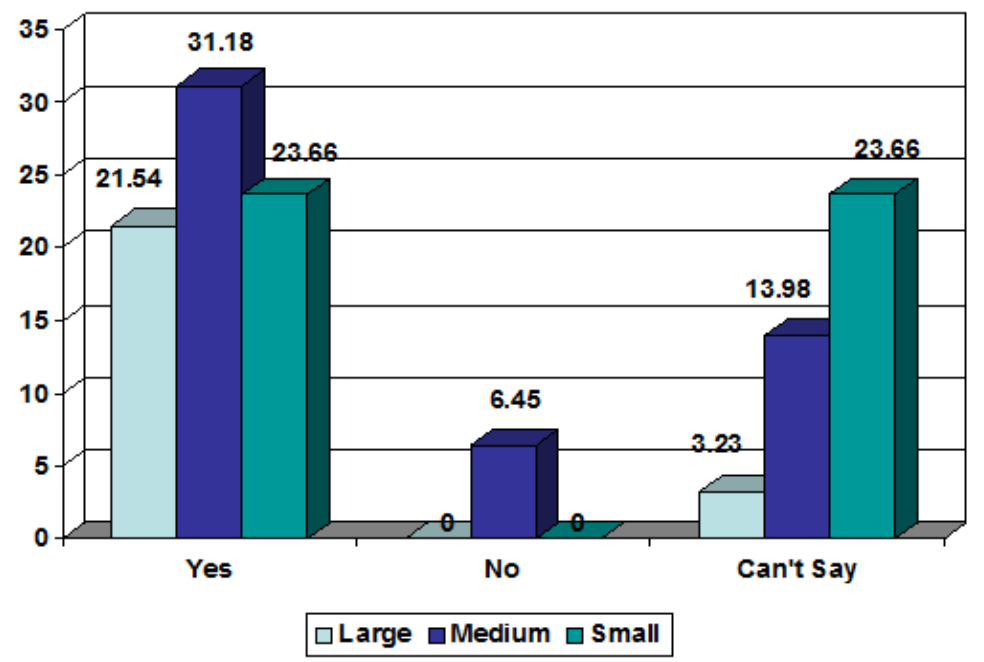

Figure3. Whether the CROs maintain sufficient working capital to operate their business.

\section{RECOMMENDATIONS FOR BUSINESS STRATEGY FOR CROS}

9.1. The businesses strategy for large organizations with turn-over above Rs. $50 \mathrm{cr}$. And above p.a., should be focused on large scale continuous investments, international customer acquisition and long term customer retention and management of attrition in the organization and technology upgradation, branding with quality while meeting the ever increasing regulatory norms and rating agency requirements. Acquisition of capital from external sources is recommended due to high cost of funds in India @ 12\% p.a. Compared to global 2.5\% p.a. This requires policy changes at Govt. level and the industry force or lobby should be strong enough to divert Govt.'s attention to solving the problems of this industry.

9.2. The medium size CROs (Rs. 10 to $50 \mathrm{cr}$. p.a.) should focus on growth with investments while competing with large CROs on one side and smaller CROs on the other, on price, quality and service. They would not be able to have everything in-house and therefore may strategize for linkages with large CROs locally and globally which will help in improving their business viability. The organizations ACRO (Association of Contract Research Organizations) should play vital role in this. They kalso should have strategies to attract Govt.'s attention to solve their problems of capital, duties and technology transfer avenues.

9.3. The Small CROs (below Rs. 10 cr p.a. Turnover) should operate in small segment by networking with small customers using the ir special skills and just in time supply capabilities which cannot be serviced by large or medium organizations. Their long term strategies should be to grow with calculated risk of investments and returns by carefully selecting markets and niche pockets which they can effectively service.

9.4. For all the three types of CROs namely large, medium and small, the following parameters serve as guideline for strategy making in each category:

\subsubsection{External Factors}

1. Regulatory issues (0.99985) preferred by Small scale CROs

2. Key Financial Ratios (0.99985) preferred by Small scale CROs

3. Financial foundation (0.99743) preferred by small scale CROs

4. Legal structures (0.99743) preferred by small scale CROs

5. Operational risk (0.99328) preferred by Large scale CROs 
6. Opportunities (0.99044) preferred by Large scale CROs.

7. Operational risk (0.98851) preferred by Medium scale CROs

9.4.2. Internal Factors: Table 2

In the final analysis, the human resource domain remains the key for success of CRO industry and HR strategy should be knitted around the following:

1. Growth opportunities - Small \& Medium CROs

2. Organization culture -Large \& Medium CROs

3. Salary - All CROs

4. Technology absorption or adoption - Large CROs

5. Promotional avenues - All CROs

6. Overall health of organization - All CROs

7. Position or Power - Large CROs

8. Increments - All CROs

Table2. Internal factors that serve as guideline for strategy making:

\begin{tabular}{|l|l|l|l|}
\hline Focus Area & Large & Medium & Small \\
\hline Technology sophistication & 0.99699 & 0.97108 & 0.08478 \\
\hline Customer focus & 0.99143 & 0.87482 & 0.97324 \\
\hline Branding & 0.97939 & 0.93701 & -0.00053 \\
\hline Return on investment & 0.97675 & 0.99804 & 0.57739 \\
\hline Legal compliance & 0.97399 & 0.85432 & 0.99316 \\
\hline Marketing & 0.95012 & 0.98797 & 0.99854 \\
\hline Accuracy (Precision) & 0.91721 & 0.94191 & 0.99157 \\
\hline Quality (Adherence to standards) & 0.80883 & 0.91502 & 0.98422 \\
\hline HR & 0.77569 & 0.49932 & -0.29789 \\
\hline Creation of social value (CSR) & 0.6669 & 0.55483 & 0.00606 \\
\hline
\end{tabular}

\subsection{Scope for Future Research}

The future research must focus on marketing strategies based on the work presented in this research and thesis.

\section{REFERENCES}

[1] Avorn J. (2004). Powerful Medicines, pp. 129-133. Alfred A. Knopf.

[2] The regulatory authority in the USA is the Food and Drug Administration; in Canada, Health Canada; in the European Union, the European Medicines Agency; and in Japan, the Ministry of Health, Labour and Welfare

[3] "Clinical trials in oncology". Stephanie Green, Jacqueline Benedetti, John Crowley (2003). CRC Press. p.1. ISBN 1-58488-302-2.

[4] "Clinical Trials Handbook". Shayne Cox Gad (2009). John Wiley and Sons. p.118. ISBN 0-47121388-8

[5] Tschanz, David W. (May/June 1997). "The Arab Roots of European Medicine". Saudi Aramco World 48 (3): 20-31.

[6] D. Craig Brater and Walter J. Daly (2000), "Clinical pharmacology in the Middle Ages: Principles that presage the 21st century", Clinical Pharmacology \& Therapeutics 67 (5), p. 447-450 [448].

[7] "James Lind: A Treatise of the Scurvy (1754)". 2001. Retrieved 9 September 2007. 